\title{
Long ischaemic stricture of the interposed colon
}

\section{J K PYE, JOHN WONG}

From the Department of Surgery, University of Hong Kong, Queen Mary Hospital, Hong Kong

\begin{abstract}
A case is reported of a long segment stricture in a colonic oesophageal replacement with radiographic evidence to support the diagnosis of ischaemia. Ischaemia of the substitute organ following oesophageal resection is a well recognised, serious complication that usually results in anastomotic leakage. If the anastomosis heals primarily, late manifestations of ischaemia are rare.

Ischaemia of the substitute organ following oesophageal resection is a well recognised, serious complication that usually results in anastomotic leakage. If the anastomosis heals primarily, late manifestations of ischaemia are rare. A case of a long segment stricture in a colonic oesophageal replacement is reported, with radiographic evidence to support the diagnosis of ischaemia.
\end{abstract}

\section{Case report}

A 71 year old Chinese man presented with a six month history of progressive dysphagia. This was found to be due to an adenocarcinoma at $41 \mathrm{~cm}$, extending from the cardia on to the lesser curvature of the stomach. At operation there was no evidence of metastatic spread, and a transhiatal, total oesophagogastrectomy was performed and the right hemicolon was interposed orthotopically. The upper anastomosis was to the oesophagus in the neck and the lower anastomosis to the duodenum. The bowel preparation was poor, and he had a rather stormy postoperative course, which included a left subphrenic abscess and wound dehiscence. He did, however, recover and was discharged from hospital able to swallow normally. He presented with recurrent dysphagia two months after his initial operation. A barium swallow (fig 1) showed a long stricture in the colon from D4 to D7-8. Fibreoptic endoscopy showed a smooth, fibrous stricture 14 $\mathrm{cm}$ long, starting $2 \mathrm{~cm}$ beyond the anastomosis. Biopsies did not show any recurrence of malignancy. Further investigation with a superior mesenteric arteriogram (fig 2) showed the middle colic artery to be visualised only to D10. The stricture was managed conservatively with bouginage, resulting in relief of dysphagia.

Address for reprint requests: Professor John Wong, Department of Surgery, University of Hong Kong, Queen Mary Hospital, Hong Kong.

Accepted 15 April 1988

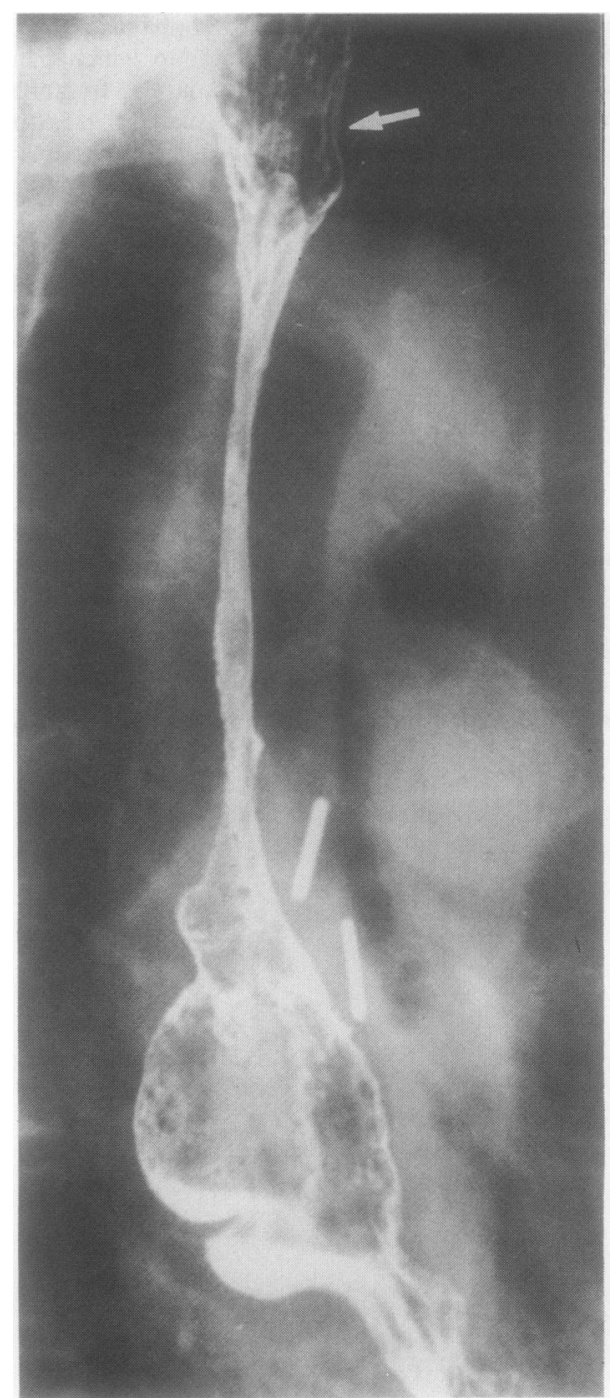

Fig 1 Barium swallow showing a long smooth stricture of the colon transplant. The arrow indicates the level of the anastomosis. Note that the stricture is proximal to the surgical clips and that the vasculature stops distal to the clips (see fig 2). 


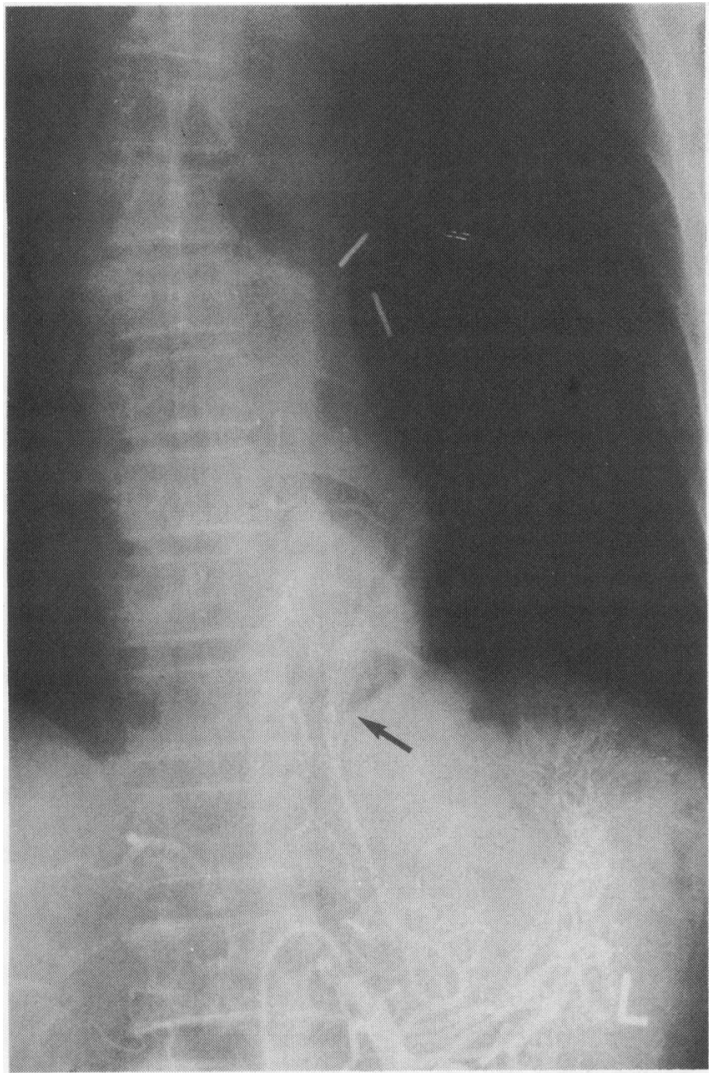

Fig 2 Superior mesenteric angiogram showing a vascular pedicle passing into the chest. The marginal arcade stops at the level of D12 (arrow) and no vasculature can be seen above D10. The stricture is proximal to the surgical clips some distance away from the demonstrable vasculature (see fig 1).

\section{Discussion}

The most common postoperative complications of oesophageal surgery relating to the substitute are anastomotic leakage, anastomotic stricture, and acute ischaemia of the substitute organ. Intrathoracic leakage and gangrene of the substitute both pose a major threat to the patient's life. ${ }^{12}$ Both may be due to technical failure, either anastomotic or arising from the preparation of the interposition loop and its vascular pedicle. ${ }^{34}$ Short segment anastomotic stricture is often associated with non-fatal anastomotic leakage, ${ }^{13-6}$ and may also be associated with reflux of gastric contents ${ }^{34}$ or recurrent malignancy.' Long segment fibrous stenosis of the interposed colon is an uncommon complication, with only nine other published cases. Linder and Hecker in 1962 made the first report ${ }^{7}$; of the other eight patients, ${ }^{3568}$ six required further surgery.
An unusual aspect of this particular complication is that all $^{5-8}$ but one ${ }^{3}$ of the reported cases had primary anastomotic healing, with the stricture presenting no earlier than one month postoperatively. The stricture may affect all or part of the colon loop. In our case the stricture affected about $40 \%$ of the interposition with sparing of the proximal $2 \mathrm{~cm}$. The other reported cases had either segmental ${ }^{357}$ or total interposition strictures. ${ }^{68}$ Most authors have considered ischaemia, either arterial ${ }^{58}$ or venous, ${ }^{26}$ to be the underlying cause. Indirect evidence for this has been provided by two authors. Harvey and Kettlewell ${ }^{8}$ documented a period of postoperative hypotension and hypoxia, followed by "thumbprinting" of the colonic mucosa, on a barium swallow five days postoperatively, characteristic of ischaemic colitis. Larson et al ${ }^{5}$ found that either necrosis or stricturing occurred in those patients whose preoperative angiogram showed an interrupted marginal artery. In addition, Hong $e t$ $a l^{6}$ postulated that venous stasis with subsequent thrombosis might be responsible, as they noted that the colon in the neck often looked deeply congested.

Our patient had arterial insufficiency demonstrated and we presume this to be the cause. It does not, however, explain why the proximal $2 \mathrm{~cm}$ should be spared, and why in most such cases there is no anastomotic leak. The ischaemia may have a delayed onset, allowing primary anastomotic healing with subsequent stricture formation. Our case was complicated by abdominal sepsis, which could have compromised the blood supply; but in none of the other cases were similar incidents reported to account for delayed ischaemia. Another possibility is occlusion of one or more radial branches of the marginal artery. This might occur secondary to hypotension but was reported in only one case. ${ }^{8}$

Fibrous stenosis of the interposed colon is uncommon, but its development poses a major challenge if further surgery is required. The mechanism of ischaemia in these cases, with the exception of one, ${ }^{8}$ is not clear, making precise preventive measures difficult. Awareness of this complication, however, should be one more reason to treat the blood supply of the colonic interposition with the greatest care.

\section{References}

1 Stephens HB. Colon bypass of the esophagus. Am J Surg 1971;122:217-22.

2 Belsey R. Reconstruction of the oesophagus. Ann R Coll Surg Engl 1983;65:360-4.

3 Belsey R. Reconstruction of the oesophagus with left colon. J Thorac Cardiovasc Surg 1965;49:33-55.

4 Skinner DB. Esophageal reconstruction. Am J Surg 1980;139: $810-4$.

5 Larson III TC, Shuman LS, Libshitz HI, McMurtrey MJ. Complications of colonic interposition. Cancer 1985;56:681-90.

6 Hong PW, Seel DJ, Dietrick RB. The use of colon in the surgical treatment of benign stricture of the esophagus. Ann Surg 1964;160:202-9.

7 Linder F, Hecker WC. Oesophagusersatz durch Colon. Chirurg 1962;33:18-23.

8 Harvey JG, Kettlewell MGW. An unusual complication of colonic interposition for oesophageal replacement. Thorax 1979; 34:408-9. 